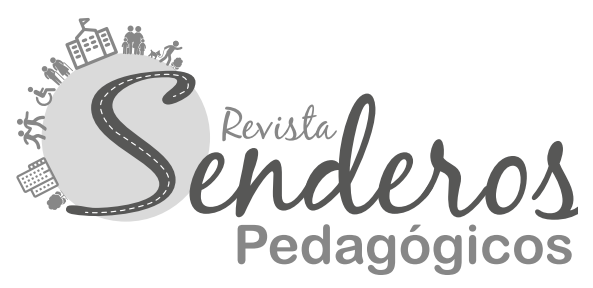

\title{
La herencia inmaterial del narcotráfico. A propósito de Era más grande el muerto de Luis Miguel Rivas ${ }^{1}$
}

The immaterial heritage of drug trafficking. About Era más grande el muerto of Luis Miguel Rivas

\author{
Autor: \\ Hermes Osorio Cossio 2 \\ https://orcid.org/0000-0003-0657-1106 \\ Recibido: 17/09/2021 \\ Aprobado: $30 / 10 / 2021$
}

1 Artículo de opinión.

2 Doctor en Historia, Universidad Nacional de Colombia; Magíster en Lingüística, Universidad de Antioquia; Psicólogo, Universidad de Antioquia; miembro del Grupo de Investigación en Historia Social (GIHS); docente de la Licenciatura en Literatura y Lengua Castellana y de la Maestría en Educación del Tecnológico de Antioquia Institución Universitaria.

hermes.osorio@tdea.edu.co.

\section{Resumen:}

En este artículo se efectúa un recorrido por las marcas que ha dejado el narcotráfico en la sociedad a partir del análisis y comentario de Era más grande el muerto (2017) de Luis Miguel Rivas. El escenario de la narración está ubicado en Villalinda, una recreación de la Medellín de los años ochenta y noventa del siglo pasado. La novela refleja con crudeza y humor los ideales, principios y aspiraciones que marcaron el derrotero de la sociedad en las últimas décadas, no solo en Antioquia o Colombia, sino en muchos países de la región. La frontera entre lo legal y lo ilegal, entre lo correcto y lo que no, cada vez aparece más difusa, los narcos pasan de las listas de la Interpol a las series de Netflix sin apenas diferencia en la valoración social. Esta obra permite por lo menos interrogar y cuestionar el brillo que series televisivas y demás quieren endosarle a estos personajes.

Palabras clave: literatura latinoamericana, análisis literario, problemas sociales, cultura de masas. 


\section{Abstract:}

This article takes a walk for the marks left by drug trafficking in societies based on analysis and commentary of Era más grande el muerto (2017) of Luis Miguel Rivas. The story has place in Villalinda, a recreation of 80's and 90's Medellín from past century. The novel reflects with rawness and humor the ideals, principles and aspirations that marked society in last decades, not only in Antioquia or Colombia but in many Latin-American countries. The border between legal and illegal, right and wrong, it appears commonly diluted, narcos goes from the Interpol lists to Netflix series with hardly any difference in social valuation. This novel takes us to ask ourselves and question the brightness that the television series and transmedia want to endorse on these characters.

Keywords: Latin American Literature, literary analysis, social problems, mass culture.

En el curso de Didáctica de la lengua castellana del segundo semestre del 2020 de la Licenciatura en Literatura y Lengua Castellana del Tecnológico de Antioquia - Institución Universitaria, implementé la metodología del Aprendizaje Basado en Problemas (ABP) para hacer un recorrido por la historia de Colombia a través de su literatura. Inicialmente, por subgrupos se abordó cada uno de los periodos de la historia, ubicando los hechos más importantes y rescatando las obras representativas del periodo. Luego, de manera individual, se leyó y expuso una novela contemporánea que abordara alguno de los distintos eventos que marcaron la historia del último siglo en Colombia. Este artículo pretende retratar mi experiencia de lectura con la novela que elegí: Era más grande el muerto (2017a) de Luis Miguel Rivas 3 .

Uno de los temas más recurrentes en las obras literarias, desde la Conquista, pasando por la Colonia y la Independencia, hasta nuestros días, es la recreación de la violencia en sus múltiples manifestaciones. Unas formas de violencia son más visibles y estruendosas: el desplazamiento forzado, las masacres, la violación o la corrupción política; otras son tenues y soterradas, y en esta medida más incrustadas en nuestra concepción del mundo: la mercantilización del cuerpo, el afán del dinero fácil, los estereotipos de belleza que imponen y determinan conductas.

Muchas de las representaciones sociales de los colombianos están cifradas en una naturalización de la violencia, tanto que no perciben sus efectos, por más que por todos lados proliferen canciones, novelas, películas y series que ubican

\footnotetext{
3 Luis Miguel Rivas (Cartago, 1969). Escritor, libretista y realizador audiovisual colombiano. Ha colaborado con las revistas El Malpensante y SoHo; los diarios El Colombiano, El Espectador y Universo Centro. Ha publicado: Los amigos míos se viven muriendo (2007), Tareas no hechas (2014), ¿Nos vamos a ir como estamos pasando de bueno? (2015), Era más grande el muerto (2017). En 2011 fue seleccionado por la Feria Internacional del Libro de Guadalajara como uno de "Los 25 secretos mejor guardados de América Latina".
} 
a los narcos, y a su santo patrón, Pablo Escobar 4 , como objetos de admiración a través del temor, el cual soporta las políticas de seguridad (Rodríguez-Blanco y Mastrogiovani, 2018, p. 96). Es un discurso paralelo en el que por un lado está el Estado, con sus leyes e instituciones, y por el otro están quienes realmente ejercen el poder; es decir, quienes gobiernan las aspiraciones y deseos de la población. Esas manifestaciones sutiles de la violencia, ese proceso mediante el cual el narcotráfico fue permeando las prácticas cotidianas es retratado con ingenio y agudeza por Luis Miguel Rivas en su primera novela.

"Era más grande el muerto" solía escucharse cuando alguien llevaba una prenda que le quedaba holgada, cuando de lejos se notaba que no le pertenecía. Al lado de este dicho había otra expresión que le hacía pareja, "el que con lo ajeno se viste, en la calle lo desvisten". Ambos fraseologismos, o frases hechas, que conservan y expresan la sabiduría popular de las gentes y garantizan el entendimiento (Zuluaga, 1997, p. 631), enmarcan la narración. En efecto, Era más grande el muerto (2017a) es una novela popular, en el sentido que rescata el habla del pueblo; sin pretensiones ni complejos de inferioridad, escrita por un sinvergüenza; es decir, por alguien que no teme mostrarse quizá peor de lo que es. Lo que más resalta de la prosa es la inocencia y desparpajo con la que un narrador omnisciente y el personaje principal van contando una serie de hechos cotidianos y nimios en medio de un mundo social que se resquebraja a punta de balas y bombazos; eso sí, a ritmo de tangos, baladas, vallenatos, boleros y "música americana”.

La historia comienza con la descripción de los zapatos de Chepe: "Los zapatos más caros y más pinchados y que dieran más estatus que usted pudiera imaginarse en la Villalinda de esa época" (Rivas, 2017a, p. 9). Estos zapatos fueron a parar a los pies de Yovani, quien los compró en la morgue cuando ya Chepe no los iba a necesitar nunca más, y fue el motivo por el cual se conoció con Manuel, narrador y personaje principal de la historia. Este par de impávidos jóvenes, desesperados por conseguir plata "pa'la mecha", viven una serie de peripecias y aventuras por andar vestidos con la ropa de un muerto que la organización mafiosa de la ciudad tuvo que matar en varias ocasiones; en esa ciudad se mata hasta a los cadáveres.

Estos zapatos de Chepe, que daban el mayor estatus que se pudiera imaginar, cierran también la narración. Manuel pretende conservarlos luego de que su amigo más cercano muriera por el estallido de una bomba: "Pasé los dedos por los taches de la suela y al llegar al talón halé. Descalcé a Yovani. Iba a meter los zapatos a la mochila cuando sentí a los policías encima y los dejé caer al suelo”. Manuel suelta los zapatos, acepta perder lo que daba más brillo en esa ciudad,

4 Pablo Emilio Escobar Gaviria (Rionegro, 1949 - Medellín, 1993). Fue un narcotraficante, terrorista y político colombiano, fundador y máximo líder del Cartel de Medellín. 
la apariencia de una vida opulenta y llena de fantasías realizadas, y continúa su camino. La respuesta que le da a quien se acerca a pedirle dinero, describe su estado: “-No hay nada hermano" (Rivas, 2017a, p. 397).

La prosa es ágil y directa, sin digresiones, ni eufemismos. Presenta una variación ortográfica que remite a la invención de José Saramago ${ }^{5}$, quien utilizaba en sus relatos las mayúsculas después de coma para marcar o indicar la entrada de otra voz. Empero, el caso de Rivas es aún más radical, pues utiliza la mayúscula, con este mismo fin, pero sin estar antecedida de ningún signo de puntuación:

\begin{abstract}
Acabé de desayunar y llevé el plato a la cocina con mi mamá detrás y lavé la loza oyendo el chorro cayendo en la vajilla mezclado con la voz chillona Es que no sirven es pa'taco ninguno de los dos, creen que la plata cae del cielo, no valoran todo el sacrificio que uno hace, y puse a secar la loza en la canastica de plástico rojo, y fui a lavarme los dientes [...] (Rivas, 2017a, p. 162).
\end{abstract}

La cantaleta de la madre es un ingrediente esencial en la dieta de Manuel, hasta la arepa le sabe a cantaleta. Si bien Manuel es quien cuenta la historia que se va desarrollando en un presente continuo, hay otro personaje sobre el que gravita la narración, uno que encarna el "patrón" del mal.

Claramente es una ficción, la obra no se inscribe en lo que se denomina novela histórica, o la novela-ensayo al estilo de Enrique Vila Matas ${ }^{6}$, o la novelacrónica como le gusta jugar a Javier Cercas?

La historia trascurre en Villalinda, una recreación de la Medellín de los años ochenta y noventa del siglo pasado. Años aciagos de la guerra de los carteles de la droga y contra estos, época que podría definirse como la "era de Pablo Escobar", ahora más promocionada que nunca en novelas, películas y series ${ }^{8}$ repletas de los lugares comunes que propagan la leyenda por todo el mundo. Contrario al manual de cómo triunfar con esas historias sin mucho esfuerzo, Rivas ofrece

5 José de Sousa Saramago (Azinhaga, 1922 - Tías, 2010). Fue un dramaturgo, novelista, poeta y periodista portugués. Premio Nobel de Literatura en 1998. Entre sus obras más relevantes se encuentran: El Evangelio según Jesucristo (1991), Ensayo sobre la ceguera (1995), Las intermitencias de la muerte (2005).

6 Enrique Vila-Matas (Barcelona, 1948). Ensayista y novelista español. Entre sus novelas más importantes están: Historia abreviada de la literatura portátil (1985), Bartleby y compañía (2000), París no se acaba nunca (2003).

7 Javier Cercas (Cáceres, 1962). Escritor, docente y periodista español. Entre sus obras más notables destacan: Soldados de Salamina (2001), La velocidad de la luz (2005), Anatomía de un instante (2009).

8 Entre las novelas más relevantes sobre Pablo Escobar se encuentran: Amando a Pablo, odiando a Escobar (2007) de Virginia Vallejo, Noticia de un secuestro (1996) de Gabriel García Márquez, La parábola de Pablo (2001) de Alonso Salazar, Matar a Pablo Escobar (2001) de Mark Bowden, Pablo Escobar, mi padre (2014) de Juan Pablo Escobar. Películas tales como: Get Shorty (1995), Pablo Escobar: King of Cocaine (1998), Ciudadano Escobar (2004), Blow (2001), Escobar: Paradise Lost (2014), American Made (2017), Loving Pablo (2017). Series de Netflix: Pablo Escobar: el patrón del mal (2012), Narcos (2015), Sobreviviendo a Escobar, Alias JJ (2017) (serie basada en el libro Sobreviviendo a Escobar (2015) de Jhon Jairo Velázquez), Señores de la droga (2018), Entre auténticos narcos (2018). 
otra mirada a este fenómeno, acerca al lector a la consolidación del narcotráfico desde su propagación e implementación en las prácticas cotidianas. El escritor vallecaucano logra captar esa transición en las trasformaciones urbanas con una sutileza llena de ingenio e ironía:

Uno podía ir por la calle y decir, Los de aquella casa de ventanales polarizados y balcones de mármol coronaron, Aquellos vecinos que tienen un solo garaje y echaron plancha apenas están comenzando, A los de esa casa que se quedó con el cuarto piso a la mitad y el hueco de la piscina sin terminar se les cayó el viaje, Estos del antejardín con enanos de colores y el jacuzzi en el balcón están trabajando con los más duros, El de la esquina que mantiene el mismo moridero de toda la vida no está en la pomada. Y así (Rivas, 2017a, p. 326).

El pegamento, la razón por la que se mantienen gran parte de los conflictos es la riqueza antes que la pobreza. Si bien Rivas quería contar la historia desde la perspectiva de Manuel, un chichipato en sus términos (Rivas, 2017b), un joven del común, sin plata, ni trabajo, ajeno al sicariato y al narcotráfico, al retratar a Don Efrén, uno de los “dones” y manda-callar de Villalinda, muestra que los que tienen mucho dinero igual se comportan como chichipatos. La narración muestra que, a los ricos, incluso más que a los pobres, les preocupa aparentar antes que ser. Así, Don Efrén quiere rodearse de arte y cultura, no como un fin en sí mismo, sino como un ardid o estratagema para alcanzar un propósito ordinario.

Don Efrén contrata a un asesor para que le diera clases de decencia, buenos modales y cultura. La misión del asesor es mejorar su imagen ante el público de la ciudad, pero principalmente ante los ojos de Lorenita, única mujer que se había atrevido a despreciarlo, y por bruto. Don Efrén solo pretendía que esta lo quisiese, así tuviera que incursionar en eso de la cultura para conseguirlo: "Vea, mijo, hágame el favor de ir a la librería y me trae tres volquetadas de libros de los más bonitos, y que cuando Salsa arrancó lo volvió a llamar, No, vea, mejor tráigame también feos, mezcladitos, que haya pa’todos los gustos" (Rivas, 2017a, p. 114). Pero no basta con esas excentricidades para que el patrón estuviera seguro de que el plan para conquistar a Lorenita funcionara, ya que el asesor le había dicho que no era solo cuestión de cantidad, sino de calidad, así que le encarga que le consiga el libro más caro del mundo:

— Y cuál es la güievonada que tiene pues esto pa’valer tanto -dijo al fin el patrón.

- Es por lo antiguo. Y por lo que está escrito, por lo que dice ahí -le contestó el asesor. 
- Y cómo va a saberse lo que dice ahí si no se entiende.

- Es que está en inglés antiguo.

- Pues claro que debe ser inglés porque no se entiende. Yo tampoco soy tan bruto pa'no darme cuenta. ¿Pero qué dice ahí?

- Son los salmos de la Biblia.

- ¿Cómo así? ¿O sea que dice lo mismo que dice en la biblia que tengo en el nochero?

- Pues... sí señor.

- ¿Pagué cinco millones de dólares por un libro que ya tengo? iNo me crea tan pendejo! (Rivas, 2017a, p. 114).

Pronto Don Efrén se impacienta con tanta cultura, deja el traje nuevo del emperador y se muestra tal como era: "Vea, mijo, no perdamos más tiempo. Yo no sirvo pa'esto. Le voy a ser sincero, para lo único que necesito la cultura es pa'levantarme una chimba que me tiene enyerbado y le gustan esas cosas" (Rivas, 2017a, p. 262). El duro de la ciudad, a quien la mitad de la ciudad teme y la otra lo admira, ese que se conquistó el corazón de los jóvenes, es tan solo un "vivo" que vive con la muerte encima y la riega por todos lados.

Si Colombia es un país de chichipatos, lo es no solo por los pobres que le venden el alma al diablo, creyendo que así realizarán sus sueños de ascenso económico, lo es principalmente porque muchos ricos (nuevos y viejos) saben que les basta con aparentar ser honestos para apropiarse de los recursos públicos; que amasan y amansan sus fortunas a costa de saquear las arcas de un Estado que los ampara y desvía la mirada para iluminar la delincuencia común y la inseguridad. Esta es la herencia inmaterial que nos dejó el narcotráfico, la cual han entendido muy bien los "nuevos narcos", quienes ya no se van lanza en ristre contra el gobierno, sino que asisten como invitados de honor a la posesión presidencial.

Recrear el pasado reciente, como lo hizo Rivas en Era más grande el muerto (2017a), permite acercar al lector a la comprensión de la realidad nacional, sin patetismos ni melodramas. El humor es un poderoso antídoto para no sucumbir ante la desesperanza, ni caer en amarillismos taquilleros. Es importante conocer la historia, no como suele decirse, para no repetirla, sino precisamente para darnos cuenta de su repetición. El narcotráfico es hoy lo que es, una marca distintiva de los colombianos en el exterior, no porque existan otros Pablos, sino porque la sociedad en general, quizá sin ser consciente de ello, incorporó esos valores y principios: admiración por el vivo, desprecio por el bobo; justificar cualquier medio mientras dé dinero; preferir al "emprendedor" antes que al rigor en la formación o creer que sin tetas grandes no hay redención.

Más allá de esto, la lectura de esta novela y las discusiones que se tejieron durante el curso de Didáctica de la lengua castellana hicieron palpable la función 
de la educación: contrarrestar con el amor a los libros y al saber, la pasión por la ignorancia. En tiempos en que vivir es una guerra de ratas por ascender en la pirámide del éxito, la educación, el amor por el saber, es lo único que nos puede librar por momentos del "sálvese quien pueda". El amor, como la amistad, está hecho de esas simples acciones que nos dan felicidad, el rescate de estas simples actividades, tal vez puedan servir de talismán frente a la violencia que nos rodea.

\section{Referencias}

Rivas, L. (2017a). Era más grande el muerto. Seix Barral.

Rivas, L. (2017b). No somos un país de sicarios, somos un país de chichipatos. Revista Semana. https://www.semana.com/cultura/articulo/luis-miguel-rivas-era-masgrande-el-muerto/540930/.

Rodríguez-Blanco, S., y Mastrogiovanni, F. (2018). Narrativas hegemónicas de la violencia. El crimen organizado y el narcotráfico entre el periodismo y la ficción televisiva. Anàlisi, 58, 89-104.

Zuluaga, A. (1997). Sobre las funciones de los fraseologismos en textos literarios. Paremia, 6, 631-640. 